
Gas 2

Kadek Mikewati $^{\mathrm{a}}$, Sidrotul Muntaha ${ }^{\mathrm{b}}$ dan Okvita Wahyuni ${ }^{\mathrm{c}}$

\title{
PEMBONGKARAN LIQUEFIED PETROLEUM GAS (LPG) DENGAN SHIP TO SHIP OPERATION DI VLGG PERTAMINA GAS 2
}

\author{
Kadek Mikewati $^{\mathrm{a}}$, Sidrotul Muntaha ${ }^{\mathrm{b}}$ dan Okvita Wahyuni $^{\mathrm{c}}$ \\ ${ }^{a}$ Taruna (NIT. 49124485.N) Program Studi Nautika PIP Semarang \\ ${ }^{\mathrm{b}}$ Dosen Program Studi Nautika PIP Semarang \\ ${ }^{c}$ Dosen Program Studi KALK PIP Semarang
}

\begin{abstract}
ABSTRAK
LPG merupakan muatan gas yang dicairkan yang terdiri dari butane dan propane. Pembongkaran LPG di VLGC Pertamina Gas 2 dilakukan dengan Ship to Ship Operation. Berdasarkan hasil penelitian, pembongkaran LPG mengalami ketidaklancaran. Maka penulis tertarik untuk mengangkat rumusan masalah untuk dibahas dalam judul "Pembongkaran Liquefied Petroleum Gas (LPG) dengan Ship to Ship Operation di VLGC Pertamina Gas 2”. Penulis menggunakan metode kualitatif studi kasus untuk menguraikan kasus-kasus yang terjadi dan menjelaskan upaya yang dilakukan untuk mengatasi kendala-kendala, antara lain pengetahuan beberapa ABK yang masih kurang, kurangnya koordinasi antara pihak kapal dengan pihak yang terkait serta peralatan bongkar tidak dalam kondisi normal. Beberapa upaya untuk mengatasinya dengan cara peningkatan pengetahuan ABK dengan mengadakan pengenalan dan pelatihan kepada seluruh crew dek mengenai pelaksanaan prosedur bongkar muatan, tugas dan tanggung jawab, peningkatan koordinasi antara pihak kapal dengan pihak yang terkait serta melakukan perawatan yang rutin terhadap alat-alat pembongkaran dan peralatan penunjang lainnya.
\end{abstract}

Kata kunci: LPG, bongkar, ship to ship

\section{PENDAHULUAN}

Liquefied Petroleum Gas (LPG) merupakan gas minyak bumi yang dicairkan, di mana campurannya terdiri dari berbagai unsur hidrokarbon yang berasal dari gas alam dengan komponen utama yaitu unsur propana $\left(\mathrm{C}_{3} \mathrm{H}_{8}\right)$ dan unsur butana $\left(\mathrm{C}_{4} \mathrm{H}_{10}\right)$. LPG juga mengandung hidrokarbon ringan lain dalam jumlah kecil, misalnya etana $\left(\mathrm{C}_{2} \mathrm{H}_{6}\right)$ dan pentana $\left(\mathrm{C}_{5} \mathrm{H}_{12}\right)$.

Sarana transportasi laut yang memenuhi kriteria untuk hal ini adalah tipe kapal tanker jenis gas carrier yang didesain khusus untuk mengangkut muatan gas dalam bentuk cair. Kapal tanker pengangkut LPG merupakan kapal yang khusus dibangun untuk mengangkut LPG dalam jumlah yang besar, kapasitasnya antara $3.000 \mathrm{~m}^{3}$ sampai $85.000 \mathrm{~m}^{3}$. Kapal pengangkut LPG merupakan sarana transportasi yang paling efisien, karena yang diangkut adalah gas alam yang telah dicairkan. Dimana rasio perbandingan antara volume gas LPG bila menguap dengan gas LPG dalam keadaan cair bervariasi tergantung komposisi tekanan dan temperatur, untuk LPG biasanya sekitar 250 berbanding 1. Sehingga dapat dibayangkan bahwa sebuah kapal pengangkut LPG yang mengangkut gas alam yang telah dicairkan akan sebanding dengan 250 kapal pengangkut gas yang muatannya masih dalam bentuk gas. 
Jurnal Dinamika Bahari

Vol. 8 No. 2 Edisi Mei 2018

Jenis-jenis kapal tanker pengangkut LPG di dunia ada 3 jenis kapal, fully pressurised, semi refrigerated dan fully refrigerated. LPG pertama kali yang dipasarkan ke pelayaran internasional diangkut dalam tangki dengan tekanan silinder LPG sistem fully pressurized. Kapal jenis fully pressurised memiliki sejumlah kekurangan pada daya angkut yang sangat kecil sekitar $2.500 \mathrm{~m}^{3}$. Beberapa tahun kemudian tepatnya pada tahun 1959, kapal pertama dengan sistem semi-didinginkan atau semi refrigerated yang memiliki kemampuan lebih banyak dalam membawa muatan karena memiliki sistem yang dapat mendinginkan muatan. Pada tahun 1960-an desain kapal baru dengan sistem fully refrigerated dibangun dengan ukuran $28.875 \mathrm{~m}^{3}$ dan mengalami perkembangan desain dengan ukuran yang lebih besar agar dapat meningkatkan kapasitas muatannya sebanyak 75.000$85.000 \mathrm{~m}^{3}$ yang tergolong menjadi kapal VLGC (Very Large Gas Carrier).

Di Indonesia kapal jenis VLGC banyak digunakan sebagai kapal pengambil LPG pertamina, dikarenakan pemerintah telah membuat keputusan mengganti bahan bakar minyak menjadi bahan bakar gas yang mana lebih menguntungkan dari segi ekonomis dan lingkungan. VLGC Pertamina Gas 2 sebagai salah satu kapal jenis Very Large Gas Carrier yang dibeli oleh PT. Pertamina sebagai kapal pengambil muatan dan storage gas yang melayani pembongkaran LPG ke semua tipe kapal gas.

VLGC Pertamina Gas 2 beroperasi di Indonesia yaitu di pelabuhan Kalbut dan Teluk Semangka untuk melayani kapalkapal gas yang akan memasok ke berbagai daerah di Indonesia seperti Jawa Timur, Bali, Sulawesi, Kalimantan dan Jakarta. VLGC Pertamina Gas 2 saat pembongkaran LPG dengan Ship to Ship Operation. Pada saat pelaksanaan pembongkaran muatan LPG tersebut, terjadi ketidaklancaran yang menghambat pembongkaran LPG antara lain pengetahuan beberapa ABK yang masih kurang mengenai prosedur pembongkaran, kurangnya koordinasi antara pihak kapal dengan pihak yang terkait serta alat pembongkaran tidak dalam kondisi normal.

Bila ditinjau dari ketidaklancaran yang ada pada saat pembongkaran LPG, maka harus diperlukan upaya untuk menangani ketidaklancaran tersebut, agar proses pembongkaran berlangsung secara optimal dan tidak terjadi kegagalan saat proses bongkar muatan yang akan mengakibatkan kerugian bagi pihak perusahaan karena keterlambatan pembongkaran muatan yang akan didistribusikan keseluruh area yang dilayani. Dari penjelasan di atas maka perlu dilakukan penelitian sehingga penulis tertarik untuk mengangkat masalah yaitu, "Mengapa terjadi ketidaklancaran dalam pembongkaran Liquefied Petroleum Gas (LPG) dengan Ship to Ship operation di VLGC Pertamina Gas 2?"

Untuk menghindari perluasaan masalah, maka penulis hanya membahas tentang ketidaklancaran dalam pelaksanaan pembongkaran Liquefied Petroleum Gas (LPG) dengan Ship to Ship operation dan upaya yang dilakukan untuk mengatasi ketidaklancaran tersebut. Di mana penelitian yang dilakukan oleh penulis yaitu selama melaksanan praktek di VLGC Pertamina Gas 2 yaitu pada tanggal 12 Agustus 2014 sampai dengan 23 Agustus 2015. Adapun tujuan penelitian ini yaitu untuk mengetahui penyebab terjadinya ketidaklancaran serta upaya yang dilakukan untuk mengatasi ketidaklancaran saat pembongkaran LPG secara Ship To Ship di kapal VLGC Pertamina Gas 2.

\section{KAJIAN PUSTAKA}

A. Bongkar

Metode pembongkaran LPG tergantung dari jenis kapal, spesifikasi 

Gas 2

Kadek Mikewati $^{\mathrm{a}}$, Sidrotul Muntaha ${ }^{\mathrm{b}}$ dan Okvita Wahyuni ${ }^{\mathrm{c}}$

muatan, dan penyimpanan di terminal. Tiga metode yang dapat digunakan yaitu:

1. Discharge by pressurising the vapour space

Pembongkaran dengan tekanan menggunakan vaporizer dan compressor di atas kapal jenis tangki tipe C. Metode pembongkaran ini membutuhkan waktu yang lama dan terbatas untuk kapal berukuran kecil. Metode alternatif adalah menekan muatan ke tangki yang lebih rendah dari pompa terminal.

2. Discharging by pump

Sebuah pompa sentrifugal harus dimulai dengan valve yang tertutup rapat atau terbuka sebagian untuk meminimalkan beban awal. Setelah itu, discharge valve dibuka perlahan sampai beban pompa dalam parameter yang aman dan muatan berpindah ke darat. Sebagai hasil pembongkaran, level muatan di dalam tangki harus dipantau. Proses pembongkaran harus hati-hati untuk menjaga stabilitas kapal dan stres lambung. Pembongkaran muatan oleh pompa sentrifugal dengan menggunakan pompa muatan atau dalam seri dengan booster pump adalah metode yang digunakan sebagian besar kapal dan pemahaman mengenai karakteristik sangat penting dalam pembongkaran yang efisien.

3. Discharging via booster pump and cargo heater

Di mana muatan yang sedang dibongkar dari sebuah refrigerated ship ke dalam pressurized ship, maka diperlukan untuk menghangatkan muatan (biasanya paling sedikit $0{ }^{\circ} \mathrm{C}$ ). Ini berarti dengan menjalankan booster pump dan cargo heater seri dengan pompa muatan. Namun, apabila jarak pembongkaran tidak jauh, maka booster pump tidak perlu digunakan, karena di sini fungsi dari booster pump adalah untuk menambah tekanan sehingga muatan dapat dipindahkan.

\section{B. Liquefied Petroleum Gas}

1. Propane merupakan anggota dari alkane atau paraflin series of hydrocarbon yang merupakan gas yang tidak berwarna dan mudah terbakar pada tekanan atmosfer dan suhu normal serta memiliki bau gas alam yang khas. Sama halnya dengan Propane, Butane juga merupakan anggota dari alkane atau paraflin series of hydrocarbon. Butane merupakan gas yang tidak berwarna, mudah dicairkan, mudah terbakar, tidak larut dalam air dan sedikit larut dalam alkohol serta tidak berbau.

2. This is abbreviation for Liquefied Petroleum Gas. This group of product includes propane and butane which can be shipped separately or as a mixture. LPG may be refenery by-products or may be produced in conjunction with crude oil or natural gas.

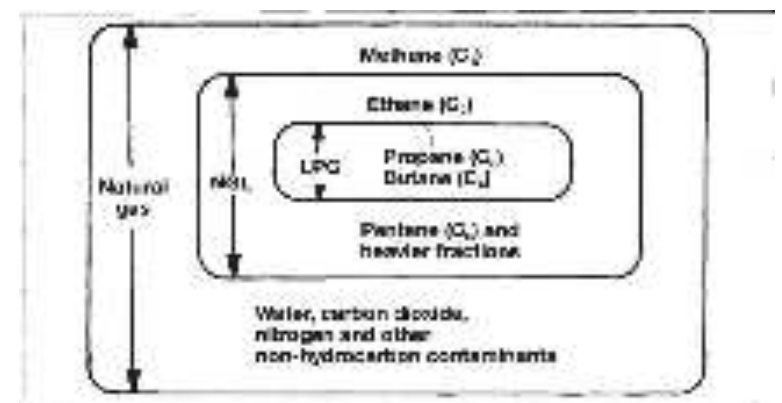

Gambar 1: Diagram antara gas $L P G, N G L$ dan $L N G$

\section{Ship to Ship Operation}

1. To Ship (STS) transfer operation is an operation where liquid or gaseous cargo is transferred between ships moored side by side. Such operations may take place when one ship is at anchor or alongside or when both are 
underway. In general, the expression includes the approach manoeuvre, mooring, hose connection, procedures for cargo transfer, hose disconnection, unmooring, and departure manoeuvre.

Yang artinya yaitu sebuah operasi di mana muatan cair atau gas yang dipindahkan antara kapal-kapal yang ditambatkan satu sama lain. Di mana salah satu kapal berlabuh jangkar atau sandar atau saat keduanya berlayar. Secara umum, pelaksanaannya mulai dari olah gerak kapal saat kapal tiba, penambatan kapal, pemasangan hose, prosedur transfer muatan, pelepasan hose, pelepasan tambat kapal, dan olah gerak pada saat kapal akan berangkat.

2. Ship to ship activity means any activity not related to a port facility that involves the transfer of goods or person from one ship to another.

\section{Kapal LPG}

Kapal gas adalah kapal barang yang dibangun dan dirancang untuk dapat mengangkut muatan secara curah semua jenis gas yang dicairkan. Kapal gas dibagi beberapa jenis menurut muatannya antara lain:

\section{Fully pressurised ship}

Kapal fully pressurised merupakan tipe kapal yang paling sederhana dari semua tipe pengangkut gas, membawa muatan pada suhu ambient dengan tipe tangki muatan " $\mathrm{C}$ " yang mempunyai tekanan sekitar 18 bar, mempunyai kapasitas ruang muatan antara $4.000 \mathrm{~m}$ sampai $6.000 \mathrm{~m}$ kapal ini digunakan untuk membawa LPG dan amonia.

\section{Semi pressurized ship}

Kapal tipe semi pressurised ini merupakan jenis kapal yang dapat melakukan pemuatan dan pembongkaran secara fully refrigerated dan fully pressurised, mempunyai volume muat antara $3.000 \mathrm{~m}$ sampai $15.000 \mathrm{~m}$ dengan suhu yang dingin antara $4^{\circ} \mathrm{C}$ sampai $8^{\circ} \mathrm{C}$ dan tekanan antara 3.5 bar sampai 4.5 bar, kapal ini dapat memuat muatan LPG dalam bentuk fully refrigrated dan fully pressurised.

3. Ethylene and gas / chemical carrier

Kapal ini mempunyai kelebihan dengan dapat memuat muatan selain muatan LPG, kapal ini dapat memuat ethylene yang mempunyai boiling point $-104^{\circ} \mathrm{C}$, serta mempunyai kapasitas ruang muat antara $1.000 \mathrm{~m}$ sampai $12.000 \mathrm{~m}$, dengan specific gravity 1.8 pada temperatur minimum $-104^{\circ} \mathrm{C}$ sampai $+80^{\circ} \mathrm{C}$, kapal tipe ini dapat melakukan pemuatan dan pembongkaran secara pressurised dan refrigerated.

4. Fully refrigerated ship

Kapal dengan kapasitas ruang muat besar yang berkisar antara $20.000 \mathrm{~m}$ sampai $100.000 \mathrm{~m}$ dapat memuat muatan dengan temperatur $-48^{\circ} \mathrm{C}$, jenis muatan yang dapat dimuat oleh kapal tipe ini yaitu: LPG, ammonia, and vinyl chloride.

5. Liquefied Natural Gas (LNG) carrier Kapal ini mempunyai kapasitas antara $125.000 \mathrm{~m}$ sampai $135.000 \mathrm{~m}$, Muatan LNG diangkut dalam temperatur $-162{ }^{\circ} \mathrm{C}$, kapal ini hanya dapat memuat muatan jenis LNG atau muatan gas chemical lainnya. 

Gas 2

Kadek Mikewati $^{\mathrm{a}}$, Sidrotul Muntaha ${ }^{\mathrm{b}}$ dan Okvita Wahyuni ${ }^{\mathrm{c}}$

\section{METODOLOGI}

\section{A. Kerangka Pemikiran}

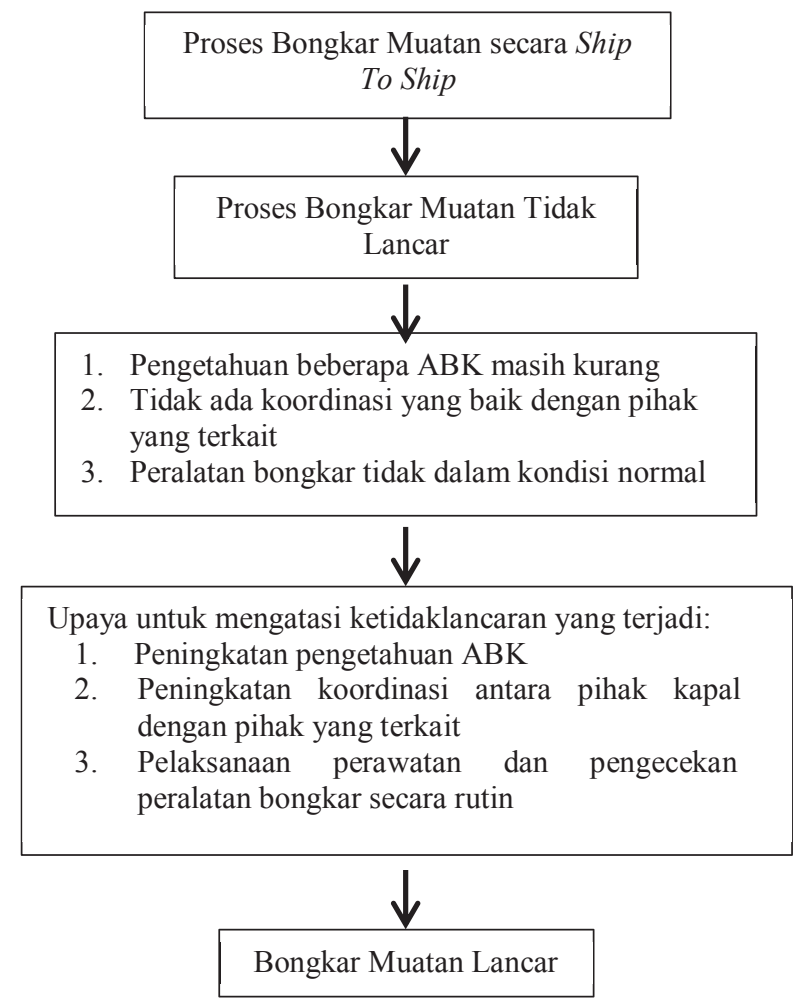

Gambar 2 : Kerangka Pikir Penelitian

\section{B. Metodologi Penelitian}

Dalam penelitian ini, metode penelitian yang digunakan penulis dalam menyampaikan masalah adalah kualitatif studi kasus. Metode penelitian kualitatif ditujukan untuk penelitian yang bersifat mengamati kasus. Dengan demikian, proses pengumpulan data dan analisis data bersifat kasus pula. Penelitian studi kasus atau penelitian lapangan dimaksudkan untuk mempelajari secara intensif tentang latar belakang masalah keadaan dan posisi suatu peristiwa yang sedang berlangsung saat itu, serta interaksi lingkungan unit sosial tertentu yang bersifat apa adanya.

C. Waktu dan Tempat Penelitian

Dalam melaksanakan penelitian ini penulis mengadakan observasi langsung ke objek penelitian, yaitu dengan melaksanakan praktek laut selama 12 bulan yang dimulai pada bulan agustus 2014 sampai dengan bulan agustus 2015 di atas kapal VLGC Pertamina Gas 2 yang memiliki panjang keseluruhan 225,81 m dengan GRT 48.917 MT dan DWT 54.626 MT. Kapal VLGC Pertamina Gas 2 milik dari PT. Pertamina dengan alamat perusahaan Jl. Yos Sudarso No. 32-34, Tanjung Priok-Jakarta.

\section{Data yang Diperlukan}

Dari sebuah penelitian akan dihimpun data-data utama dan sekaligus data tambahannya. Sumber data utama dalam penelitian kualitatif ialah kata-kata dan tindakan, sedangkan data tertulis, foto, dan statistik adalah data tambahan.

\section{E. Metode Pengumpulan Data}

Metode pengumpulan data merupakan teknik atau cara yang dapat digunakan oleh peneliti untuk pengumpulan data. Pengumpulan data dimaksudkan untuk memperoleh bahan-bahan yang relevan, akurat, dan nyata. Untuk memperoleh data-data tersebut dengan cara antara lain seperti: wawancara, observasi, dan kepustakaan. Masing-masing data memiliki kelebihan dan kekurangan sendiri-sendiri. Oleh karena itu, lebih baik mempergunakan suatu pengumpulan data lebih dari satu, sehingga dapat saling melengkapi satu sama lain.

Di dalam penelitian ini menggunakan beberapa teknik pengumpulan data, antara lain:

1. Metode wawancara mendalam Wawancara mendalam adalah suatu kegiatan yang dilakukan untuk mendapatkan informasi secara langsung dengan mengajukan pertanyaan kepada narasumber (informan) untuk mendapatkan informasi yang mendalam. Pelaksanaan wawancara dilakukan dengan para awak kapal VLGC 
Jurnal Dinamika Bahari

Vol. 8 No. 2 Edisi Mei 2018

Pertamina Gas 2 yaitu Master Capt. Reymond Paparang, Chief Officer Hadi Wibowo, $2^{\text {nd }}$ Officer Arendra Pramadikya, $3^{\text {rd }}$ Officer Panji Pratama, $4^{\text {th }}$ Officer Burhanudin, Gas Engineer Sigit Tri Wahyu Haryadi dan bosun Jonder Nainggolan dengan menggunakan cara terpimpin, yaitu pewawancara membuat kerangka dan garis besar pokok-pokok pertanyaan. Antara lain tentang kapal dan muatan LPG, prosedur proses bongkar muatan secara ship to ship, safety di atas kapal, kendala-kendala yang dihadapi dan cara mengatasinya.

2. Metode Observasi

Observasi difokuskan sebagai upaya peneliti mengumpulkan data dan informasi dari sumber data primer dengan mengoptimalkan pengamatan peneliti. Dalam penelitian ini, teknik penelitian yang dilakukan juga melibatkan aktivitas mendengar, membaca, mencium, dan menyentuh. Apabila objek penelitian bersifat perilaku dan tindakan manusia, fenomena alam (kejadian-kejadian yang ada di sekitar alam kita), proses kerja, dan penggunaan responden kecil, maka tehnik observasi digunakan dengan maksud untuk mendapatkan atau mengumpulkan data secara langsung selama melaksanakan praktek laut di VLGC Pertamina Gas 2.

3. Analisa dokumentasi

Teknik pengumpulan data melalui analisa dokumentasi diartikan sebagai upaya untuk memperoleh data dan informasi berupa catatan tertulis / gambar yang tersimpan berkaitan dengan proses bongkar muatan secara ship to ship di kapal LPG. Dokumen berupa fakta dan data tersimpan dalam berbagai bahan yang berbentuk dokumentasi.

4. Studi kepustakaan

Studi kepustakaan merupakan penelitian yang dilakukan untuk menghimpun dan menganalisis data yang bersumber dari buku-buku literatur. Studi pustaka juga merupakan pelengkap di dalam teknik pengumpulan data terutama apabila terdapat kesulitan dalam pemecahan masalah dengan mempelajari teori-teori yang berhubungan dengan permasalahan.

5. Penelusuran data online

Penulis juga melakukan pengumpulan data melalui internet, di mana penulis mendapatkan informasi yang terbaru dan seluasluasnya di dunia maya. Data-data ini digunakan untuk memperkuat sumber-sumber lainnya yang telah didapat.

\section{F. Teknik Analisis Data}

Analisis data kualitatif dicirikan dengan sifat-sifat tertutup, jangka masa panjang, dan mendalam. Tidak heran jika kemudian, dalam analisis ini ada yang bersifat kembali lagi ke lapangan seperti dalam analisis interaktif. Analisis interaktif yaitu mendeskripsikan analisis yang diarahkan untuk menjejaki hubunganhubungan yang sah dan stabil di antara fenomena sosial.

Dalam penelitian ini, peneliti menganalisis data dengan model interaktif, dimana model ini memiliki tiga komponen, yaitu:

1. Reduksi data (data reduction)

2. Tampilan data (data display). Kegiatan menampilkan data adalah mengorganisasi, meringkas, dan menyambungkan informasi.

3. Kesimpulan yang digambarkan dan diverifikasi. Alasan perlunya reduksi dan display data adalah 

Gas 2

Kadek Mikewati $^{\mathrm{a}}$, Sidrotul Muntaha ${ }^{\mathrm{b}}$ dan Okvita Wahyuni ${ }^{\mathrm{c}}$

untuk membantu menggambarkan kesimpulan.

\section{DISKUSI}

A. Gambaran Umum

1. Gambaran Umum VLGC
Pertamina Gas 2
VLGC Pertamina Gas 2 adalah
sebuah kapal Very Large Gas Carrier jenis fully refrigerated milik PT. Pertamina yang mengangkut muatan LPG berupa butane $\left(\mathrm{C}_{4} \mathrm{H}_{10}\right)$ dan propane $\left(\mathrm{C}_{3} \mathrm{H}_{8}\right)$. Awalnya kapal VLGC Pertamina Gas 2 hanya sebagai storage ship di pelabuhan Kalbut, Situbondo. Di mana muatan diterima dari kapal-kapal charter import dan kemudian dibongkar kembali ke kapal-kapal yang berukuran lebih kecil yang akan dibongkar ke pelabuhan-pelabuhan Indonesia. Kemudian mulai bulan Februari 2015, kapal VLGC Pertamina Gas 2 mengambil muatan dari pelabuhan muat antara lain Bontang, RuwaisUnited Arab Emirate dan Ras LaffanQatar, kemudian dikirim ke Teluk Semangka dan Kalbut Situbondo sebagai tempat bongkar. Proses bongkar muatan dilakukan dengan ship to ship operation. Jadi selama penulis melakukan penelitian di VLGC Pertamina Gas 2, kapal ini hanya melakukan proses bongkar muatan dengan ship to ship operation.

VLGC Pertamina Gas 2 memiliki Call sign YDFN (Yankee Delta Foxtrot November) dengan isi kotor 48.917 MT dan isi bersih 15.575 MT serta memiliki Deadweight (DWT) Summer 54.626 MT. Ukuran-ukuran pokok kapal diantaranya, panjang kapal 225,81 m dan lebar kapal 36,60 m serta memiliki Depth moulded to main deck (jarak vertikal dari lunas sampai dek utama) 20,30 m. Kapal
VLGC Pertamina Gas 2 memiliki crane dengan jumlah 3 unit yang masing-masing memiliki SWL 10 MT yang berada di geladak utama di dekat manifold, sedangkan 2 lainnya merupakan provision crane (katrol pengangkut persediaan kapal) berada di samping kiri dan kanan anjungan kapal dengan SWL masing-masing 0.9 MT. Kapal VLGC Pertamina Gas 2 memiliki tangki berjenis independent tank type "A", dengan kapasitas total tangki muatan 84.155,753 $\mathrm{m}^{3}$. Peralatan bongkar yang dimiliki antara lain: cargo pump (pompa muatan) 2 unit di setiap tangki yang berjumlah 8 (kanan dan kiri), 4 cargo compressor (3 untuk propane dan 1 untuk butane), 1 unit cargo vaporizer, 1 unit cargo heater, dan 2 unit booster pump. Badan kapal ini terbuat dari baja dan bahan utama untuk tangkinya terbuat dari carbon-manganese yang mampu menahan suhu sampai dengan $-55^{\circ} \mathrm{C}$, dibuat di Hyundai Heavy Industries, Co.Ltd, Korea. (sumber : ship particular VLGC Pertamina Gas 2)

2. Gambaran Umum Pembongkaran LPG secara Ship to Ship

Di kapal VLGC Pertamina Gas 2, saat melakukan bongkar muatan ke kapal LPG tipe fully pressurize dilaksanakan secara bergantian, di mana muatan butane terlebih dahulu dibongkar dan dilanjutkan dengan muatan propane. Berbeda dengan pelaksanaan bongkar muatan ke kapal LPG tipe fully refrigerated dan tipe semi refrigerated dilakukan secara simultant yaitu muatan butane dan propane dibongkar secara bersamaan. Proses bongkar muatan secara ship to ship ini dapat dibagi menjadi beberapa tahap yang harus diperhatikan yaitu persiapan 
alongside, setelah alongside, selama proses bongkar muatan, dan setelah proses bongkar muatan yang akan dipaparkan sebagai berikut:

\section{a. Persiapan alongside}

Sebelum kapal melakukan proses bongkar muatan, maka shutle ship akan melakukan manoeuvering dan mooring dengan kapal mother ship yang berlabuh jangkar. Untuk itu harus dilakukan komunikasi mengenai apa yang harus diperhatikan oleh kedua kapal. Komunikasi yang sangat penting ini meliputi:

1) Penggunaan channel radio dan mempersiapkan channel lain apabila terjadi hambatan pada channel utama.

2) Bahasa yang digunakan selama operasi ship to ship berlangsung serta waktu harus disinkronkan antara kedua kapal.

3) Rencana penyandaran dan olah gerak kapal harus dimengerti dan disetujui antara kedua kapal. Termasuk penataan letak dan ukuran fenders harus sedemikian rupa agar mother ship dan shutle ship tidak berbenturan.

4) Mooring arrangement harus disepakati dan dilaksanakan.

5) Peralatan olah gerak, penambatan tali-tali dan peralatan navigasi harus diuji dan dalam keadaan siap digunakan.

6) Transfer of personnel antara kedua kapal.

7) Susunan manifold dan lifting gear harus diketahui kedua kapal.

8) Menyegarisluruskan manifold muatan antara kedua kapal. b. Setelah alongside

Sesudah kapal menempel atau alongside maka kedua kapal menyiapkan hal-hal berikut ini:

1) Penggunaan channel radio dan mempersiapkan channel lain jika terjadi kerusakan pada channel utama pada saat transfer muatan.

2) Ukuran cargo transfer hose yang digunakan sehubungan dengan pemasangan reducer pada manifold.

3) Pertukaran informasi mengenai Material Safety Data Sheet (MSDS).

4) Dokumen-dokumen muatan yang dibutuhkan.

5) Menyediakan alat-alat pemadam kebakaran di manifold meliputi portable dan fix pemadam kebakaran. Serta pompa hydrant pada posisi siap digunakan.

6) Menaikkan bendera B (bravo).

7) Memulai cargo hose handling.

8) Pengecekan cargo transfer hose apakah ada kebocoran setelah melakukan leak test.

9) Cargo transfer system safety device termasuk inert gas, emergency signal dan emergency shutdown (ESD) system dapat berfungsi.

10) Line up pipa-pipa muatan dari cargo pump sampai ke manifold.

c. Selama proses bongkar muatan

Selama proses bongkar muatan berlangsung perlu diadakan pengawasan dengan tujuan untuk menghindari hal-hal yang membahayakan baik bagi kapal itu maupun terminal dermaga sebagai tempat sandar. Tindakan-tindakan pengamanan yang harus dipatuhi 

Gas 2

Kadek Mikewati $^{\mathrm{a}}$, Sidrotul Muntaha ${ }^{\mathrm{b}}$ dan Okvita Wahyuni ${ }^{\mathrm{c}}$

selama proses bongkar muatan secara ship to ship meliputi:

1) Selama proses bongkar muatan harus dicek berapa muatan yang sudah dibongkar yaitu dengan menghitung ullage (ruang kosong tangki). Dengan diketahuinya jumlah muatan di dalam tangki maka dapat diketahui rate per-jamnya (rata-rata bongkar per jam).

2) Menjaga tekanan pompa jangan sampai over speed dan menjaga tekanan dalam pipa karena bila tekanan sangat rendah maka cargo pump akan mati.

3) Suhu muatan pada manifold juga harus diperhatikan sesuai dengan permintaan kapal penerima muatan terutama saat bongkar muatan dengan tipe kapal yang berbeda.

4) Pengecekan terhadap sambungan-sambungan cargo transfer hose dan area di sekitar manifold.

5) Pengecekan terhadap posisi fenders dan tali-tali tambat kapal karena posisi kapal saling berkaitan.

6) Pengecekan terhadap posisi kapal karena kapal pada posisi berlabuh jangkar.

7) Stabilitas kapal harus benarbenar diperhatikan oleh perwira jaga.

8) Mengadakan pengawasan di area samping kapal karena dikhawatirkan banyak perahu nelayan di sekitar area kapal yang sedang melakukan pembongkaran.

d. Setelah pembongkaran

Setelah melaksanakan proses bongkar muatan harus dilaksanakan pembersihan line dengan cara blowing dengan vapour yang diambil dari dalam tangki muatan. Kemudian setelah proses bongkar muatan selesai kedua kapal melakukan pengecekan tangki-tangki muatan, kemudian dilakukan perhitungan bila telah sesuai dengan Bill of Lading (BL) maka dapat diselesaikan semua dokumen muatan dan bisa dilaksanakan disconnect cargo transfer hose dan shuttle ship siap untuk lepas sandar

B. Analisa Masalah

Berdasarkan observasi dan analisa objek secara langsung di atas kapal, selama proses bongkar muatan berlangsung tidak luput dari kendalakendala yang terjadi yaitu adanya ketidaklancaran dalam proses bongkar muatan tersebut. Ketidaklancaran yang menjadi masalah dalam proses bongkar muatan LPG di kapal VLGC Pertamina Gas 2 adalah :

1. Pengetahuan beberapa ABK masih kurang

Pengetahuan dari beberapa ABK yang masih kurang mengenai bagaimana prosedur pembongkaran yang sesuai dengan standar aman dan aturan yang berlaku. Dan juga tindakan yang tidak disiplin sehingga sikap ceroboh dan meremehkan segala sesuatu atas dasar pengalaman yang mereka miliki selama bekerja di kapal sebelumnya.

2. Tidak ada koordinasi yang baik dengan pihak terkait

Kurangnya koordinasi antara pihak kapal (mother ship) dengan pihak kapal penerima muatan (shuttle ship) dan juga kurangnya koordinasi dari pihak kapal baik dari pihak mother ship maupun shuttle ship dengan pihak pelabuhan sehingga sering 
terjadi kesalahpahaman dan perubahan jadwal Ship to Ship yang tidak terkoordinir dengan baik yang menyebabkan proses pembongkaran sering mengalami keterlambatan.

3. Peralatan bongkar tidak dalam kondisi normal

Faktor peralatan bongkar muatan yang tidak dalam kondisi normal dapat menyebabkan terganggunya proses bongkar muatan dikarenakan kurangnya perawatan dan pengecekan peralatan bongkar tersebut.

C. Pembahasan Masalah

Dalam pembahasan masalah ini penulis mencoba untuk memberikan pemecahan-pemecahan masalah yang terjadi di VLGC Pertamina Gas 2 khususnya pada saat pembongkaran LPG secara ship to ship. Pembahasan tersebut meliputi:

1. Ketidaklancaran Pada Saat Pembongkaran LPG Secara Ship to Ship (STS) di VLGC Pertamina Gas 2

Berdasarkan observasi dan analisa objek secara langsung di atas kapal, ketidaklancaran yang menjadi permasalahan keterlambatan proses bongkar muatan LPG di kapal VLGC Pertamina Gas 2 adalah :

a. Pengetahuan beberapa ABK masih kurang

Pengetahuan beberapa ABK yang masih kurang tentang bagaimana prosedur pembongkaran yang sesuai dengan standar aman dan aturan yang berlaku. Dan juga tindakan yang tidak disiplin sehingga sikap ceroboh dan meremehkan segala sesuatu atas dasar pengalaman yang mereka miliki selama bekerja di kapal sebelumnya.
Beberapa hal yang terkait dengan faktor anak buah kapal adalah :

1) Kurangnya pengetahuan beberapa ABK mengenai kapal LPG tipe full refrigerated

Kurangnya pengetahuan dari ABK tentang kapal LPG terutama tipe fully refrigerated menjadi salah satu kendala, dikarenakan sebagian besar pengalaman ABK VLGC Pertamina Gas 2 adalah di kapal oil tanker dan atau di kapal LPG tipe fully pressurize. Di VLGC Pertamina Gas 2, hanya Nahkoda, Mualim 2 dan Gas Engineer saja crew deck yang memiliki pengalaman di kapal LPG tipe fully refrigerated selebihnya pengalaman crew deck yaitu di kapal oil tanker dan di kapal LPG tipe fully pressurize. Dan pada saat crew pertama kali onboard di atas kapal, crew diberikan kesempatan untuk melaksanakan pengenalan kapal, namun saat pelaksanaan pengenalan, minimnya data lisan maupun data tertulis yang diterima oleh crew baru pada saat pergantian crew.

Dari hasil observasi, penulis mendapatkan beberapa kejadian yang penulis alami pada saat melaksanakan praktek di VLGC Pertamina Gas 2:

a) Pada tanggal 1 Desember 2014, lokasi Pelabuhan Kalbut, Situbondo. Mualim 1 memerintahkan AB dan saya standby di tangki no.1 untuk mengecek keadaan tangki muatan no.1 saat akan membongkar muatan butane. $\mathrm{AB}$ menjawab 

Gas 2

Kadek Mikewati $^{\mathrm{a}}$, Sidrotul Muntaha ${ }^{\mathrm{b}}$ dan Okvita Wahyuni ${ }^{\mathrm{c}}$

lewat radio bahwa main liquid valve sudah terbuka penuh, filling valve terbuka 50\%, discharge valve terbuka $35 \%$ dan cargo pump siap untuk dinyalakan. Namun pada saat cargo pump sudah dinyalakan dan filling valve perlahan ditutup, tekanan pada main liquid valve terus bertambah dan tidak ada penambahan tekanan pada manifold liquid valve. Kemudian mulaim 1 memerintahkan saya untuk berlari ke main valve liquid pada tangki no.1 untuk memastikan sudah terbuka. Dan setelah saya cek, ternyata main liquid valve pada tangki no.1 belum terbuka kemudian saya langsung membukanya secara penuh dan akhirnya tekanan pada main liquid valve tangki no.1 mulai berkurang dan tekanan pada manifold liquid valve mulai bertambah. Setelah Mualim 1 menanyakan kembali ke $\mathrm{AB}$ mengenai hal di atas, ternyata $\mathrm{AB}$ hanya melihat tali yang ada pada main liquid valve dalam kondisi tidak terpasang. Yang mana tali itu merupakan tanda, apabila tali itu terpasang pada main liquid valve maka tandanya tertutup, apabila tidak terpasang maka tandanya main liquid valve terbuka. Ini merupakan salah satu sikap yang kurang disiplin dari $\mathrm{AB}$ yang meremehkan dan menganggap hal yang sudah biasa sehingga tidak dilakukan pengecekan.

b) Pada tanggal 13 April 2015, lokasi Pelabuhan Kalbut, Situbondo. Pada saat bongkar muatan ke kapal LPG/C Gas Natuna yang mana merupakan kapal LPG tipe full pressurize yang mana suhu muatan yang diterima lebih panas dari kapal tipe full refrigerated, sehingga pembongkaran harus menggunakan cargo heater. Saat proses pembongkaran muatan propane sedang berlangsung, Mualim 2 mengamati dari CCR terlihat bahwa suhu pada manifold liquid valve berubah-ubah tidak stabil. Setelah Mualim 2 bertanya kepada AB yang sedang bertugas jaga di dek, ternyata pada saat itu $\mathrm{AB}$ berusaha untuk inisiatif sendiri mengatur suhu pada manifold liquid valve agar segera stabil kembali tanpa melaporkan ke Mualim 2 yang sedang bertugas jaga waktu itu, hal ini dilakukan karena $\mathrm{AB}$ tersebut merasa sudah paham cara mengatur suhu pada manifold liquid valve dan mengetahui suhu yang biasanya diterima oleh kapal LPG/C Gas Natuna berdasarkan pengalaman yang biasanya dilakukan saat bongkar muatan ke 
kapal LPG/C Gas Natuna sebelumnya.

2)Kurang pengecekan di dek oleh perwira jaga saat pembongkaran muatan berlangsung

Tugas seorang perwira jaga sangat erat kaitannya dengan tanggung jawab mereka sebagai orang yang dipercaya dalam kegiatan bongkar muat.

Berdasarkan hasil wawancara yang penulis lakukan dengan responden Mualim 1 yang bernama Hadi Wibowo, dikatakan bahwa, "Mualim jaga pada saat proses bongkar muatan kurang melakukan pengawasan dan pengecekan di dek, mereka cenderung mengamati dari CCR dan hanya melakukan pengecekan pada saat tugas jaga akan berakhir, padahal mereka seharusnya melakukan pengecekan di dek tiap jam".

3) Perwira jaga harus bertanggung jawab agar kegiatan-kegiatan berikut ini dilakukan.

a) Seringkali berkeliling kapal untuk memantau:

i) Tali-tali tambat kapal terpasang dengan baik.

ii) Cargo transfer hose yang terpasang di manifold dengan keadaan baik dan tidak ada kebocoran.

iii)Saluran-saluran pipa di deck.

iv) Tempat-tempat di sekitar kapal. v) Peralatan pemadam kebakaran dan penanggulangan tumpahan minyak.

vi)Kepastian bahwa tidak ada personil yang tidak berkepentingan diperbolehkan berada di tempat-tempat muatan dan di ruang pengontrol muatan.

b) Memastikan penjagaan agar tempat di sekitar manifold selalu terpantau oleh dinas jaga di dek.

c) Memastikan bahwa $\mathrm{ABK}$ yang bertugas jaga di dek memahami tugastugasnya.

d) Operasi-operasi transfer muatan ditangguhkan jika terjadi perubahanperubahan atas kondisikondisi lingkungan yang memperlihatkan suatu bahaya untuk melanjutkan operasi.

e) Semua masukan yang diperlukan dicatat di dalam buku harian kapal.

f) Mualim 1 dipanggil jika merasa ragu untuk melakukan tugas-tugas kerjanya, atau jika ditemukan ancamanancaman terhadap kapal atau penanganan muatan.

g) Instruksi-instruksi dari Mualim 1 dipatuhi.

h) Perwira jaga wajib melakukan pemeriksaan kerja yang teratur pada awal dan selama pembongkaran untuk mengkonfirmasi bahwa tangki muatan sedang membongkar muatan sesuai rencana. 

Gas 2

Kadek Mikewati $^{\mathrm{a}}$, Sidrotul Muntaha ${ }^{\mathrm{b}}$ dan Okvita Wahyuni ${ }^{\mathrm{c}}$

i) Perwira jaga wajib mengecek di CCR maupun di dek mengenai tekanan pada pipa-pipa muatan, cargo pump dan manifold secara berkala setiap satu jam dan dicatat pada hourly cargo discharging rate log.

j) Melakukan penghitungan ullage dan tekanan muatan dan dicatat.

k) Jika ditemukan perbedaan yang besar, pembongkaran dihentikan dan harus di cek ulang secara manual banyaknya muatan di shuttle ship dengan loading master.

b. Tidak ada koordinasi yang baik dengan pihak terkait

Berdasarkan hasil wawancara yang penulis lakukan dengan responden, dikatakan bahwa pelaksanaan proses bongkar muatan ke kapal gas lain menjadi terhambat dikarenakan oleh kurangnya koordinasi antara pihak kapal (mother ship) dengan pihak kapal penerima muatan (shuttle ship) yaitu mengenai ketersediaan alat penunjangan bongkar muat. Dan kurangnya koordinasi antara pihak kapal baik pihak mother ship maupun shuttle ship dengan pihak pelabuhan mengenai jadwal penyandaran. Dan perubahan penjadwalan tidak segera diinfokan kepada pihak mother ship dan shuttle ship. Kurangnya koordinasi tersebut meliputi :

1) Kurangnya informasi alat penunjang pembongkaran muatan yang tersedia di kedua kapal
Informasi mengenai alat penunjang pembongkaran yang tersedia di kedua kapal sangat penting untuk diberikan karena tanpa informasi yang jelas, proses bongkar muatan dapat tertunda bahkan batal. Maka dari itu adapun beberapa informasi yang harus diberikan yaitu:

a) Susunan posisi manifold dari masing-masing kapal (posisi manifold liquid dan vapour untuk butane dan propane).

b) Ukuran reducer yang akan digunakan dan yang tersedia di atas kapal.

c) Initial rate, maksimum rate dan suhu muatan yang akan dibongkar.

d) Posisi tengah-tengah kapal sebagai acuan pemasangan cargo transfer hose.

e) Ukuran panjang dan lebar kapal sebagai acuan dalam peletakan fenders.

2) Kurang terjadwalnya rencana waktu pembongkaran muatan

Jadwal atau rencana waktu pembongkaran muatan sangatlah diperlukan agar kegiatan ship to ship cargo operation dapat berjalan secara teratur dan tepat waktu. Namun pada kenyataannya yang terjadi, perubahan waktu pembongkaran muatan diberikan secara mendadak dan kadang kala terdapat kesalahan dalam pemberian jadwal kapal yang seharusnya melakukan ship to ship cargo operation.

c. Peralatan bongkar tidak dalam kondisi normal

Peralatan bongkar muatan yang kurang terawat merupakan salah 
satu kelemahan dalam penanganan bongkar muatan, peralatan bongkar muat yang kurang terawat dapat mengakibatkan alat tersebut mengalami kerusakan dan tidak berfungsi dengan normal. Padahal apabila ingin penanganan pembongkaran muatan berjalan lancar, maka harus didukung oleh peralatan bongkar muat dalam kondisi yang baik dan memadai.

Adapun kejadian yang pernah dialami di VLGC Pertamina Gas 2 mengenai peralatan yang tidak dalam kondisi normal saat proses bogkar muatan secara ship to ship berlangsung, yaitu:

1) Pada tanggal 3 Januari 2015 di pelabuhan Kalbut, Situbondo. LPG/C Amelia 1 melaksanakan ship to ship operation di kapal VLGC Pertamina Gas 2. Cargo transfer hose yang berfungsi sebagai sambungan antara manifold kapal VLGC Pertamina Gas 2 dengan manifold LPG/C Amelia 1 mengalami kerusakan, akibat dari cargo transfer hose yang kondisinya sudah lama yang saat itu terjadi gerakan kapal karena adanya ombak, sehingga cargo transfer hose tersebut mengalami lekukanlekukan (gambar terlampir pada halaman lampiran). Melihat hal tersebut, proses bongkar muatan ditunda dan harus menunggu pergantian cargo transfer hose yang lain. Pihak kapal segera melaporkan ke pihak pelabuhan agar segera digantikan dengan cargo transfer hose yang baru sehingga saat pembongkaran selanjutnya tidak terdapat kendala yang sama.

2) Pada tanggal 9 Mei 2015 di pelabuhan Kalbut, Situbondo. Saat sedang melakukan pemasangan cargo hose pada LPG/C AE Gas, terjadi kebocoran oli pada cargo crane. Saat itu Bosun langsung melaporkan kepada Mualim jaga dan pemasangan cargo transfer hose ditunda. Kemudian gas engineer langsung mengecek cargo crane. Setelah diperiksa oleh gas engineer ternyata terjadi kebocoran O-ring pada limit switch wire, kemudian $O$-ring yang sudah rapuh diganti dengan yang baru dan operasi cargo crane bisa dilanjutkan.

2. Upaya-upaya yang Dilakukan Agar Proses Bongkar Muatan LPG Secara Ship To Ship Lancar

Dalam pembongkaran LPG di VLGC Pertamina Gas 2 ke kapal gas lain tidak terlepas dari kendala-kendala yang telah diuraikan di atas. Maka dari itu adapun upaya-upaya yang dilakukan untuk memperlancar proses bongkar muat secara ship to ship di VLGC Pertamina Gas 2 yaitu sebagai berikut:

a. Peningkatan pengetahuan ABK

Dari hasil wawancara dengan narasumber tentang bagaimana cara mengatasi kendala yang dihadapi dalam proses bongkar muatan $L P G$, bahwa cara mengatasi kendala mengenai peningkatan pengetahuan dan pemahaman awak kapal yaitu:

1) Mengadakan seleksi kepada seluruh anak buah kapal pada saat akan naik kapal Sebagaimana kita ketahui dalam suatu perusahaan, tentunya peranan anak buah 

Gas 2

Kadek Mikewati $^{\mathrm{a}}$, Sidrotul Muntaha ${ }^{\mathrm{b}}$ dan Okvita Wahyuni ${ }^{\mathrm{c}}$

kapal (SDM) yang memiliki pengetahuan dan keterampilan sangat berperan sekali di dalam kemajuan perusahaan itu sendiri. Begitu juga dalam penerimaan ABK baru, perusahaan perlu mengadakan seleksi kepada anak buah kapal terlebih dahulu serta mengenai persyaratan baik sertifikat maupun dokumen yang lain. Dengan mengadakan seleksi tersebut maka pihak perusahaan dapat menentukan pilihan yang terbaik bagi yang akan bekerja di atas kapal, sesuai dengan hasil seleksi yang dilakukan dan sesuai dengan penilaian sikap dari kapal sebelumnya. Tentunya yang bekerja di atas kapal merupakan orang-orang yang berkualitas dan profesional dibidangnya.

2) Pengenalan kapal kepada anak buah kapal yang baru

Untuk ABK yang baru pertama kali bekerja di atas kapal LPG dengan tipe yang berbeda, tentu banyak sekali mengalami kesulitan karena banyak sekali hal-hal yang belum diketahui terutama segala sesuatu yang menyangkut bahaya yang ditimbulkan dan prosedur bongkar muat serta pengoperasian peralatan pembongkaran. Untuk menghindari kejadian yang dapat menghambat terjadinya proses bongkar muat, maka alangkah baiknya apabila anak buah kapal yang baru naik diberikan pengarahan dan penjelasan begitu pertama kali tiba di atas kapal untuk bekerja. Karena di VLGC Pertamina
Gas 2 diperlukan penanganan muatan yang teliti, maka bagi ABK baru apabila diberi tugas harus didampingi oleh seseorang yang telah berpengalaman di atas kapal tersebut. Hal ini bertujuan agar bila ada sesuatu yang tidak diketahui oleh ABK yang baru, bisa langsung dijelaskan oleh orang yang telah berpengalaman sebelumnya.

Sehubungan dengan hal tersebut, Mualim 1 melakukan koordinasi dengan nakhoda untuk memberikan pengenalan kapal kepada seluruh crew dek saat pertama kali naik kapal tentang penanganan proses bongkar muatan serta peralatan yang menunjang. Dan Mualim 1 memastikan bahwa crew kapal yang melaksanakan pengenalan benar-benar paham dengan apa yang tertera dalam familiarization checklist.

3) Secara rutin mengadakan pelatihan tentang prosedur bongkar muat dan cargo transfer system safety device. Pelatihan untuk crew dek, terutama crew dek yang baru sangat penting untuk mencegah kesalahan prosedur yang dilakukan oleh crew dek tersebut. Dengan diadakannya pelatihan dan pengenalan kapal, diharapkan crew dek dapat mengerti dan membantu dalam penanganan bongkar muatan. Di VLGC Pertamina Gas 2, nahkoda memberikan pelatihan kepada seluruh crew dek minimal 1 bulan sekali agar mereka mengerti dan benarbenar paham tentang kapal gas. 
Pelatihan tersebut mengenai prosedur bongkar muat dan cargo transfer system safety device.

Setiap bulan juga nahkoda mengadakan safety meeting, yang akan membahas seluruh kejadian di luar dalam keadaan normal yang terjadi di atas kapal dan diakhir dari safety meeting, nahkoda mengadakan video training mengenai keselamatan di atas kapal dan dilanjutkan dengan mengadakan tes. Crew yang mendapatkan nilai terbaik akan diberikan penghargaan, sehingga crew terdorong untuk memperhatikan dan memahami video yang diputarkan. Selain itu di dalam safety meeting jug dibahas nearmiss yang telah dibuat. Yang dimaksud nearmiss disini adalah apabila salah satu crew yang menemukan suatu kejadian yang membahayakan atau di luar keadaan normal dan crew tersebut tidak berani melaporkannya, maka crew dapat menulis kejadian tersebut dan memasukkannya ke dalam kotak nearmiss yang kemudian akan dibahas dalam safety meeting.

4) Melaksanakan proses bongkar muatan sesuai dengan prosedur

Di setiap peralatan bongkar muatan, Mualim 1 sudah memberikan safety operational procedure (SOP). Maka diharapkan seluruh crew dek membaca dan memahami isi dari masing-masing SOP tersebut. Dan di CCR juga sudah terdapat chief officer standing order yang mana sudah disetujui oleh nahkoda dan ditandatangani oleh Mualim 2, Mualim 3, Mualim 4 dan gas engineer. Maka dari itu Mualim dan gas engineer wajib paham isi dari chief officer standing order tersebut dan dapat melaksanakannya dengan baik.

5) Melaksanakan pengawasan selama kegiatan bongkar muatan di dek oleh perwira jaga

Pengawasan dan monitoring kegiatan penanganan bongkar muatan di dek oleh perwira jaga harus dilakukan secara teratur minimal sekali dalam satu jam agar kegiatan yang dilakukan oleh crew yang bertugas terpantau dan mengecek benar tidaknya laporan crew di dek tentang tekanan dan suhu muatan, serta memastikan penanganan pembongkaran muatan dalam keadaan yang aman dan lancar.

Sehubungan dengan hal tersebut, Mualim 1 memberikan pengertian kepada perwira jaga untuk mengecek ke dek setiap 1 jam sekali bagaimana situasi di dek dan keadaan peralatan bongkar muatan serta Mualim 1 yang akan menggantikan perwira jaga di CCR.

6) Melaksanakan kerja sama yang baik antara crew kapal selama ship to ship operation berlangsung

Koordinasi dan kerja sama harus tetap dijaga agar di dalam melaksanakan penanganan bongkar muatan seluruh crew kapal bisa mengerti tugasnya masing-masing sehingga tercipta penanganan bongkar 

Gas 2

Kadek Mikewati $^{\mathrm{a}}$, Sidrotul Muntaha ${ }^{\mathrm{b}}$ dan Okvita Wahyuni ${ }^{\mathrm{c}}$

muatan yang lancar, aman dan sesuai prosedur. Antara crew yang berjaga di dek maupun perwira jaga harus saling mengingatkan satu sama lain. Begitu juga Mualim 1 dan nahkoda dapat mengingatkan Mualim jaga ataupun crew yang berjaga di dek agar tidak terjadi kekeliruan. Dan apabila perwira jaga ragu-ragu dalam mengambil tindakan maka dapat memanggil Mualim 1 demi kelancaran proses bongkar muatan.

b. Peningkatan koordinasi antara pihak kapal dengan pihak yang terkait

Koordinasi antara kedua kapal dan dengan pihak pelabuhan sangat berpengaruh dalam kelancaran proses bongkar muatan, sehingga di dalam operasi ship to ship ini diperlukan komunikasi yang baik antara pihak-pihak yang bersangkutan. Beberapa poin yang telah disebutkan dalam analisa hasil penelitian, memaparkan bentuk kendala yang terdapat di atas kapal di mana penulis melakukan penelitian selama praktek berlayar.

Dari hasil wawancara dengan narasumber tentang bagaimana cara mengatasi kendala terhadap kurangnya koordinasi yang ditemui tersebut, yaitu:

1) Pihak kapal (mother ship) seharusnya mendorong pihak kapal penerima muatan atau shuttle ship agar memberikan informasi yang jelas kepada mother ship mengenai peralatan bongkar muat yang tersedia.
Hal ini tentunya sangat penting karena informasi yang terkait sangat berperan dalam kelancaran proses bongkar muatan. Apabila tidak ada informasi dan koordinasi, pembongkaran akan terhambat seperti yang telah penulis paparkan sebelumnya. Yaitu pihak shuttle ship hendaknya memberikan informasi kepada pihak mother ship mengenai ukuran reducer yang tersedia, berkomunikasi dan bertukar informasi dengan kedua kapal yang akan melakukan ship to ship cargo operation mengenai tipe alat bongkar muat yang terdapat di masing-masing kapal.

2) Kedua kapal saling berkomunikasi dan saling bertukar informasi sebelum proses penyandaran, setelah penyandaran, selama pembongkaran dan setelah pembongkaran selesai.

Hal ini sudah tercantum dalam ship to ship transfer checklist dan ship/shore safety checklist. Dan kedua kapal harus benar-benar mengecek dan menjalankan apa yang telah tercantum dalam checklist tersebut. Selama proses bongkar muatan berlangsung juga harus selalu memperhatikan tinggi ullage, suhu dan tekanan sehingga apabila terjadi high pressure dan ketidakcocokan rata-rata bongkar per jam dapat langsung dikomunikasikan dengan segera. Hal ini erat kaitannya dengan jumlah muatan yang dibongkar. Agar pembongkaran ini sesuai 
dengan perjanjian antara kedua kapal yang telah tercantum dalam dokumen cargo operation agreement.

3) Penjadwalan kegiatan ship to ship cargo operation yang tepat.

Pemberian jadwal yang tepat (fixed schedule) bertujuan agar kegiatan bongkar muatan dapat berjalan tepat waktu dan sesuai dengan yang telah dijadwalkan. Sehingga saat tidak ada jadwal pembongkaran, tidak membuat ragu-ragu pihak kapal untuk melakukan pengecekan dan perawatan terhadap peralatan bongkar muat. Sehingga semua dapat berjalan sesuai dengan jadwal dan hal ini dapat meminimalisir kerugian dan finansial perusahaan.

c. Pelaksanaan perawatan dan pengecekan peralatan bongkar secara rutin

Pembongkaran muatan LPG ke kapal lain yang seharusnya dilakukan secara baik, lancar dan aman, akan tetapi karena terdapat kendala tersebut sehingga menjadi terhambat dan tidak lancar. Salah satu kelemahan dalam penanganan pembongkaran, peralatan pembongkaran yang kurang terawat dapat mengakibatkan alat tersebut mengalami kerusakan dan tidak berfungsi dengan normal. Meskipun pengecekan cargo hose dilakukan oleh pihak pelabuhan namun pihak kapal juga harus ikut serta dalam melakukan pengecekan fisik, kelayakan untuk dipakai dan memperhatikan penempatan cargo hose tersebut. Pengaturan posisi penempatan cargo hose secara sembarangan pada saat setelah pembongkaran selesai dan harus memperhatikan lekukan dari cargo hose tersebut.

Peralatan bongkar muatan yang tidak dalam kondisi normal juga dikarenakan oleh jadwal bongkar muatan yang sangat padat sehingga pihak kapal dan pelabuhan memiliki sedikit waktu untuk melakukan pengecekan dan perawatan terhadap peralatan bongkar muat.

Sehingga diperlukan kerja sama yang baik dan saling membantu dalam melaksanakan pengecekan dan perawatan tersebut. Pihak kapal harus pintar-pintar mengatur waktu agar semua dapat berjalan antara pelaksanaan bongkar muatan dan pngecekan serta perawatan alat-alat bongkar muat.

\section{KESIMPULAN}

Pada saat pelaksanaan bongkar muatan secara ship to ship, sering kali terjadi ketidaklancaran yang menghambat proses bongkar muatan, antara lain:

1. Pengetahuan beberapa ABK masih kurang.

2. Tidak ada koordinasi yang baik dengan pihak terkait.

3. Peralatan bongkar tidak dalam kondisi normal.

Dari ketidaklancaran tersebut diadakan upaya-upaya untuk mengoptimalkan proses bongkar muatan sehingga tidak terjadi keterlambatan dalam pembongkaran. Upaya-upaya tersebut antara lain: 
Pembongkaran Liquefied Petroleum Gas (LPG) Dengan Ship To Ship Operation Di VLGG Pertamina Gas 2

Kadek Mikewati $^{\mathrm{a}}$, Sidrotul Muntaha ${ }^{\mathrm{b}}$ dan Okvita Wahyuni ${ }^{\mathrm{c}}$

1. Peningkatan pengetahuan $\mathrm{ABK}$ dengan mengadakan pelatihan dan pengarahan prosedur bongkar muatan, tugas dan tanggung jawab masing-masing crew kapal.

2. Peningkatan koordinasi antara pihak yang terkait.

3. Pelaksanaan perawatan dan pengecekan peralatan bongkar secara rutin.

Dengan upaya-upaya tersebut, pembongkaran LPG dengan ship to ship operation dapat berjalan lancar apabila semua ABK memiliki pengetahuan yang lebih mengenai bongkar muatan secara ship to ship, mengerti dan terampil dalam mengoperasian peralatan, dapat melakukan koordinasi yang baik dengan pihak-pihak yang terkait serta semua peralatan pembongkaran dalam kondisi bagus dan baik.

\section{DAFTAR PUSTAKA}

Mc Guire and White. 2000. Liquified Gas Handling Principles, $3^{\text {rd }}$ edition
Indrawan dan Yaniawati. 2014. Metodologi Penelitian

2014. Tanker Management Self Assessment-Main Manual

Hyundai Heavy Industries CO. Ltd. 2013. LPG Cargo Handling System Intruction Manual

CDI, ICS, OCIMF and SIGTTO. 2013. Ship To Ship Transfer Guide (Liquefied gases), $2^{\text {nd }}$ edition

Saebani, B.A. dan Affifudin. 2012. Metode Penelitian Kualitatif.

Mustari, Mohammad. 2012. Pengantar Metode Penelitian

Liquified Gas Tanker Training Progamme Pertamina. 2012

SOLAS Consolidated. 2014

Riduwan. 2003. Metode dan Teknik Menyusun Proposal Penelitian. 